\title{
脳幹梗塞による diaschisis
}

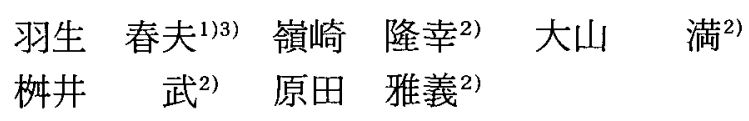

要旨：一側脳幹に限局した脳梗塞17例を対象に, SPECT による脳血流量の左右差を指標と して大脳，小脳半球に及ぼす影響を検討した。大脳半球の血流低下がみられたのは 7 例で，中 脳から橋上部までの病单では同側に，橋中部から延髄における病巣では対側に認められ，これ らの病巣はすべて脳幹被蓋を含む病巣であった，小脳半球の血流低下は 6 例にみられ，橋中部 から下部を境に上方（吻側）の病巣では対側に，下方（尾側）の病巣では同側にみられ，脳幹 腹側の病巣で認めやすい傾向にあった. 大脳半球の血流低下は発症後 $1 \sim 2$ 力月以内に認めら れたが，小脳半球の血流低下は数力月以降の慢性期にまで認められることも少なくなかった。 臨床症状との関連は不明であるが, 脳幹に限局した小病変でも遠隔領域に血流低下が出現する 場合があり，この機序として脳幹を上行，下行する投射線維を介した抑制機序，すなわち diaschisisとの関連が推測された。

Key words : brain stem infarction, diaschisis, SPECT, cerebral blood flow

(脳卒中20 : 312-317, 1998)

はじめに

中枢神経系は，機能的に連絡された豊富な神経回路 網からなるため，限局した病巣でも神経線維を介した 抑制機序から遠隔領域に機能低下が生じる。これは, diaschisis $^{1)}$ とて知られてきたが, 最近の脳循環代謝 測定法の進歩から血流や代謝の低下としてょり客観的 に，かつ定量的に評価できるようになった。

脳血管障害に伴う遠隔領域の血流や代謝の低下は, 一側大脳半球病変による健側大脳半球（transhemispheric diaschisis) や対側小脳半球 (crossed cerebellar diaschisis) ${ }^{2}$ の他にも神経線維を介してさまざまな領 域で認められ ${ }^{3 / 4)}$, remote effect と総称されているが, 脳幹病変の遠隔領域に及ぼす影響についてはあまり知 られていない(5)-7).これまで少数例でのわずかな検討 があるのみで，その意義や機序など不明な点が多い. diaschisis と同様の経神経的な抑制現象が起こり得る か否かさえも明らかにされているわけではない。そこ で今回，脳幹梗塞を対象として SPECT による脳血流
1）原田病院神経内科
2）原田病院脳神経外科
3）東京医科大学老年科
(1998年 3 月10日受付，1998年 4 月30日受理）

測定から大脳および小脸半球への影響を検討した。

\section{対象と方法}

対象は, MRI から一側脳幹に限局した梗塞巣が確認 された17例 (男性11例，女性 6 例，年齢28〜81歳) で, いずれも初回発作例である (Table 1). 梗塞部位は, 中脳が 2 例 (症例 1,2 ), 橋が 9 例 (症例 $3 \sim 11$ ), 延髄が 6 例 (症例 $12 \sim 17$, すべて延髄外側病変で既報 ${ }^{8)}$ による 4 例を含む）で，小脳半球や大脳半球に明らか な梗塞巣はみられていない。ただし, 大脳半球内には 軽度の白質病変がみられる場合もあり, 側脳室周囲の 高信号域 PVH (periventricular hyperintensity) と 深部白質内の高信号域 WMH (white matter hyperintensity)は Fazekas ら9の分類から評価した。10例に は脳血管撮影または MR angiography が施行され, 頭 蓋内外の血管病変が評価された。

SPECT 検査は, 安静臥床状態において約 $20 \mathrm{mCi}$ (740MBq) $\sigma^{99 m} \mathrm{Tc}$-hexamethyl-propyleneamine oxime を静注し, 10分後から撮像を開始した. 装置は 頭部専用リング型装置 HEADTOME SET 050 （島津 社製)で, 高分解能コリメーターを用いた。前処理フィ ルターに Butter worth, 再構成フィルターに Ramp を

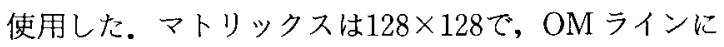


Table 1 Clinical and MRI findings

\begin{tabular}{|c|c|c|c|c|}
\hline $\begin{array}{l}\text { Patient/ } \\
\text { age/sex }\end{array}$ & Neurological findings & Infarct site on MRI & $\begin{array}{l}\text { PVH/ } \\
\text { WMH }\end{array}$ & Angiography \\
\hline $1 / 66 / \mathrm{M}$ & Lt-hemiparesis and ataxia & Rt-cerebral peduncle & $1 / 2$ & no occl. \\
\hline $2 / 63 / \mathrm{M}$ & Rt-oculomotor palsy, vertical gaze palsy & Rt-mesencephalic tegmentum & $0 / 0$ & / \\
\hline $3 / 64 / F$ & Rt-hemiplegia and ataxia, dysarthria & Lt-upper pontine basis and tegmentum & $1 / 1$ & no occl. \\
\hline $4 / 66 / \mathrm{M}$ & Rt-hemiparesis and ataxia & Lt-upper pontine basis and tegmentum & $1 / 2$ & no occl. \\
\hline $5 / 80 / \mathrm{M}$ & Rt-hemiplegia & Lt-upper pontine basis & $1 / 1$ & no occl. \\
\hline $6 / 66 / \mathrm{F}$ & Rt-hemiparesis & Lt-upper pontine basis & $1 / 0$ & 1 \\
\hline $7 / 74 / \mathrm{M}$ & $\begin{array}{l}\text { Rt-hemiparesis, dysarthria } \\
\text { Lt-MLF syndrome }\end{array}$ & Lt-midpontine basis and tegmentum & $2 / 2$ & no occl. \\
\hline $8 / 70 / \mathrm{F}$ & Lt-hemiparesis, dysarthria & Rt-midpontine basis & $1 / 1$ & / \\
\hline $9 / 76 / \mathrm{M}$ & Lt-hemiparesis & Rt-midpontine basis & $2 / 1$ & / \\
\hline $10 / 81 / \mathrm{M}$ & $\begin{array}{l}\text { Rt-ataxia, sensory deficit } \\
\text { (Rt-face/Lt-body) Rt-facial palsy }\end{array}$ & $\begin{array}{l}\text { Rt-mid-and lower pontine tegmentum, } \\
\text { Rt-middle cerebellar peduncle }\end{array}$ & $1 / 1$ & no occl. \\
\hline $11 / 77 / \mathrm{M}$ & Rt-hemiplegia & Lt-lower pontine basis & $1 / 0$ & I \\
\hline $12 / 62 / \mathrm{M}$ & $\begin{array}{l}\text { Rt-ataxia, sensory deficit (Lt-face/ } \\
\text { Lt-body), Rt-Horner's syndrome, } \\
\text { dysphagia }\end{array}$ & Rt-dorsolateral medulla & $1 / 0$ & Rt-VA occl. \\
\hline $13 / 28 / \mathrm{M}$ & $\begin{array}{l}\text { Rt-ataxia, sensory deficit (Rt-face/ } \\
\text { Lt-body), Rt-Horner's syndrome, } \\
\text { dysphagia }\end{array}$ & Rt-dorsolateral medulla & $0 / 0$ & Rt-PICA occl. \\
\hline $14 / 40 / \mathrm{F}$ & $\begin{array}{l}\text { Lt-ataxia, sensory deficit (Rt-body), } \\
\text { Lt-Horner's syndrome }\end{array}$ & Lt-dorsolateral medulla & $0 / 0$ & Lt-PICA occl. \\
\hline $15 / 69 / \mathrm{F}$ & $\begin{array}{l}\text { Lt-ataxia, sensory deficit (Lt-face/ } \\
\text { Lt body), Lt-Horner's syndrome, } \\
\text { dysphagia }\end{array}$ & Lt-dorsolateral medulla & $1 / 0$ & Lt-VA occl. \\
\hline $16 / 76 / \mathrm{M}$ & $\begin{array}{l}\text { Rt-ataxia, sensory deficit (Rt-face/ } \\
\text { Lt-body), Rt-Horner's syndrome, } \\
\text { dysphagia }\end{array}$ & Rt-dorsolateral medulla & $2 / 1$ & 1 \\
\hline $17 / 69 / \mathrm{F}$ & $\begin{array}{l}\text { Lt-ataxia, sensory deficit (Rt-body) } \\
\text { Lt-Horner's syndrome, dysphagia }\end{array}$ & Lt-dorsolateral medulla & $1 / 2$ & 1 \\
\hline
\end{tabular}

M : male, F : female, Lt : left, Rt : right, MLF : medial longitudinal fasciculus, PVH : periventricular hyperintensity, WMH : white matter hyperintensity, occl : occlusion, /: not performed, VA : vertebral artery, PICA : posterior inferior cerebellar artery

平行な，スライス間隔 $10 \mathrm{~mm}$ の水平段像を得た。本装 置の解像力 (FWHM) は約 $10 \mathrm{~mm}$ (視野中心)である.

SPECT 像より RI カウント数を測定し, その左右差 加大脳, 小脳半球の脳血流量の異常を半定量的に評 価した。既報8)のごとく, 小脳半球, 基底核部のスライ スにおける前頭葉, 側頭葉, 後頭葉皮質および側脳室 体上部のスライスに抢ける頭頂葉皮質の両側に不整形 の関心領域を設定した。各領域について asymmetry $\operatorname{index}(\mathrm{AI})=(\mathrm{R}-\mathrm{L}) /(\mathrm{R}+\mathrm{L}) / 200(\%)(\mathrm{R}$ ：右側, $\mathrm{L}$ ： 左側）算出し，健常者 10 例（平均年齢56歳，男性 4 例, 女性 6 例) と比較した。健常者の AI (平均士標準 偏差,\%)は，小脳半球： $-0.2 \pm 2.5$, 前頭枼皮質 :

$0.1 \pm 3.2$, 側頭葉皮質: $0 \pm 3.1$, 頭頂葉皮質 $: 0.1 \pm$ 3.3 , 後頭葉皮質: $0.1 \pm 3.4$ となり, 平均 \pm 2 標準偏差 を超えた低下を有意とした。

MRI は SMT $100 \mathrm{X} / \mathrm{X}(1.0 \mathrm{~T}$ ，島津社製）を用い, T1強調画像は spin echo 法 (TR：500ms, TE : 26 $\mathrm{ms}$ ), T2強調画像は高速 spin echo 法 (TR : $5,000 \mathrm{ms,}$ TE : $88 \mathrm{~ms})$ にて, FOV $25 \times 25 \mathrm{~cm}$, マトリックス $256 \times$ 256 , スライス厚 $8 \mathrm{~mm}$, 加算回数 2 回の OM ラインに 平行な軸位断層像から評価した。

\section{結果}

17例の神経症状とMRI 所見, 脳血管撮影所見を Table 1 に示す. SPECT による大脳, 小脳半球の血流 低下所見と病巣部位, 発症後時間との関連を Table 2 に示すが，血流低下領域の AI が (+) の場合は左側の 低下を，(一)の場合は右側の低下を反映する.PVH は 14例にみられ, grade 1 (側脳室前角, 後角に限局した cap または rim) から grade 2 (側脳室周团の halo)ま での範囲であった。WMH は10例にみられ，同様に grade 1または grade 2（点状高信号域の散在または一 部融合）までの比較的軽度のものばかりであった.大 脳半球の血流低下と大脳白質病変の有無との間には, 
Table 2 SPECT studies

\begin{tabular}{|c|c|c|c|c|}
\hline Patient & Time & Iesion site & Cerebral hypoperfusion & Cerebellar hypoperfusion \\
\hline 1. & 10 months & midbrain (ventral) & $(-)$ & contralateral $(+9.3 \%)$ \\
\hline 2 & 5 days & midbrain (dorsal) & ipsilateral (temporal, $-8.5 \%$ ) & $(-)$ \\
\hline 3 & 1 months & upper pons (ventral and dorsal) & ipsilateral (frontal, $+12.8 \%$ ) & contralateral $(-19.7 \%)$ \\
\hline 4 & 1 day & upper pons(ventral and dorsal) & ipsilateral(frontal, $+10.3 \%$ ) & $\cdot \quad(-)$ \\
\hline 5 & 3 months & upper pons(ventral) & $(-)$ & $(-)$ \\
\hline 6 & 2 days & upper pons (ventral) & $(-)$ & $(-)$ \\
\hline 7 & 2 months & middle pons (ventral and dorsal) & $(-)$ & contralateral $(-11.0 \%)$ \\
\hline 8 & 1 day & middle pons (ventral) & $(-)$ & $(-)$ \\
\hline 9 & 1 month & middle pons (ventral) & $(-)$ & $(-)$ \\
\hline 10 & 25 days & middle and lower pons(dorsal) & $\begin{array}{l}\text { contralateral } \\
\text { (temporoparietal, }+13.4 \%)\end{array}$ & ipsilateral $(-21.6 \%)$ \\
\hline 11 & 14 days & lower pons (ventral) & $(-)$ & ipsilateral $(+9.4)$ \\
\hline 12 & 28 days & medulla (dorsal) & contralateral (parietal, $+8.1 \%$ ) & $(-)$ \\
\hline 13 & 10 days & medulla (dorsal) & $\begin{array}{l}\text { contralateral } \\
\text { (frontotemporoparietal, }+14.7 \% \text { ) }\end{array}$ & $(-)$ \\
\hline 14 & 17 days & medulla (dorsal) & $(-)$ & $(-)$ \\
\hline 15 & 6 days & medulla (dorsal) & $(-)$ & $(-)$ \\
\hline 16 & 2 months & medulla(dorsal) & $\begin{array}{l}\text { contralateral } \\
\text { (frontoparietal, }+9.5 \% \text { ) }\end{array}$ & ipsilateral $(-7.2 \%)$ \\
\hline 17 & 25 days & medulla (dorsal) & $(-)$ & $(-)$ \\
\hline
\end{tabular}

PVH $\left(\chi^{2}=0.06\right), \mathrm{WMH}\left(\chi^{2}=0.19\right)$ 共に有意な関 連を認めなかった。延䯑道外側梗塞の 4 例で病側の椎骨 動脈または後下小脳動脈の閉塞が確認されたが，その 他の症例では天幕上下部の主要な頭蓋内外の閉塞性血 管病変を認めなかった。

大脳半球の血流低下は前頭葉加側頭葉, 頭頂葉に かけて7例 (41\%) に観察された (Table 2). 中脳か ら橋上部までの病巣では同側大脳半球の, 橋中部から 延髄における病巣では対側大脳半球の血流低下が認め られた. 脳幹腹側に限局した病巣では認められず, 背 側病変または腹側から背側にかけた病変で観察され た。 小脳半球の血流低下も6 例 (35\%) に観察された が，椎骨動脈や後下小脳動脈の閉塞とは関連を認めな かった(Table 2). 橋中部から下部を境として上方(吻 側) の病栄では対側に, 下方 (尾側) の病巣では同側 に認められ，脳幹腹側を含む病巣で出現する傾向がみ られた。ただし, 症例 9 と16は背側病変であったが, 症例 9 は中小脳脚にも病巣が及び, 症例16は延髄外側 の下小脳脚病変によるためと考えられた。

急性期から連続的に SPECT 検査が施行されたのは 一部の症例であったため,ここでは脳血流異常の経時 的な変化を明らかにすることはできず, 発症後時問と の関連から検討した。 その結果, 大脳半球の血流低下 は発症後1〜2力月以内に観察されたのに対し（6例が
1 力月以内, 1 例が 2 力月後), 小脳半球の血流低下は 数力月以降の慢性期にまで観察されることも少なくな かった ( 3 例が 1 力月以内, 3 例が $2 \sim 10$ 力月後).

小脳失調を認めた 9 例中 3 例に症状と同側の小脳半 球の血流低下を認めたが，小脳失調を認めない8例中 3 例にも小脳半球の血流低下がみられ，両所見の明確 な一致は得られなかった。

Fig. 1 に代表例（症例 3 ）のMRI, SPECT 所見を 示す.

\section{考 察}

脳幹に限局した小病変でも, 大脳，小脳半球の血流 低下は約 $41 \% ， 35 \%$ の患者で認められ，必ずしも稀な 所見ではなかった，大脳白質病変の有無や血管病変と の関連は認められず，このような遠隔部の血流低下は diaschisisとの関連が推測された。

大脳半球の血流低下は，脳幹背側（被蓋）病変で認 められ，橋上部より上方の病巣では，同側に，下方の 病巣では対側にみられたことから，脳幹被蓋を上行ま たは下行する主として交叉性の投射線維を介した抑制 機序が推測された．脳幹被蓋には多くの投射線維が分 布するが，このうち小脑（歯状核）視床皮質路や上行 性網様体賦活系からの大脳皮質投射が機能的には重要 と思われる，小脳視床皮質路は，上小脳朋を介して橋 

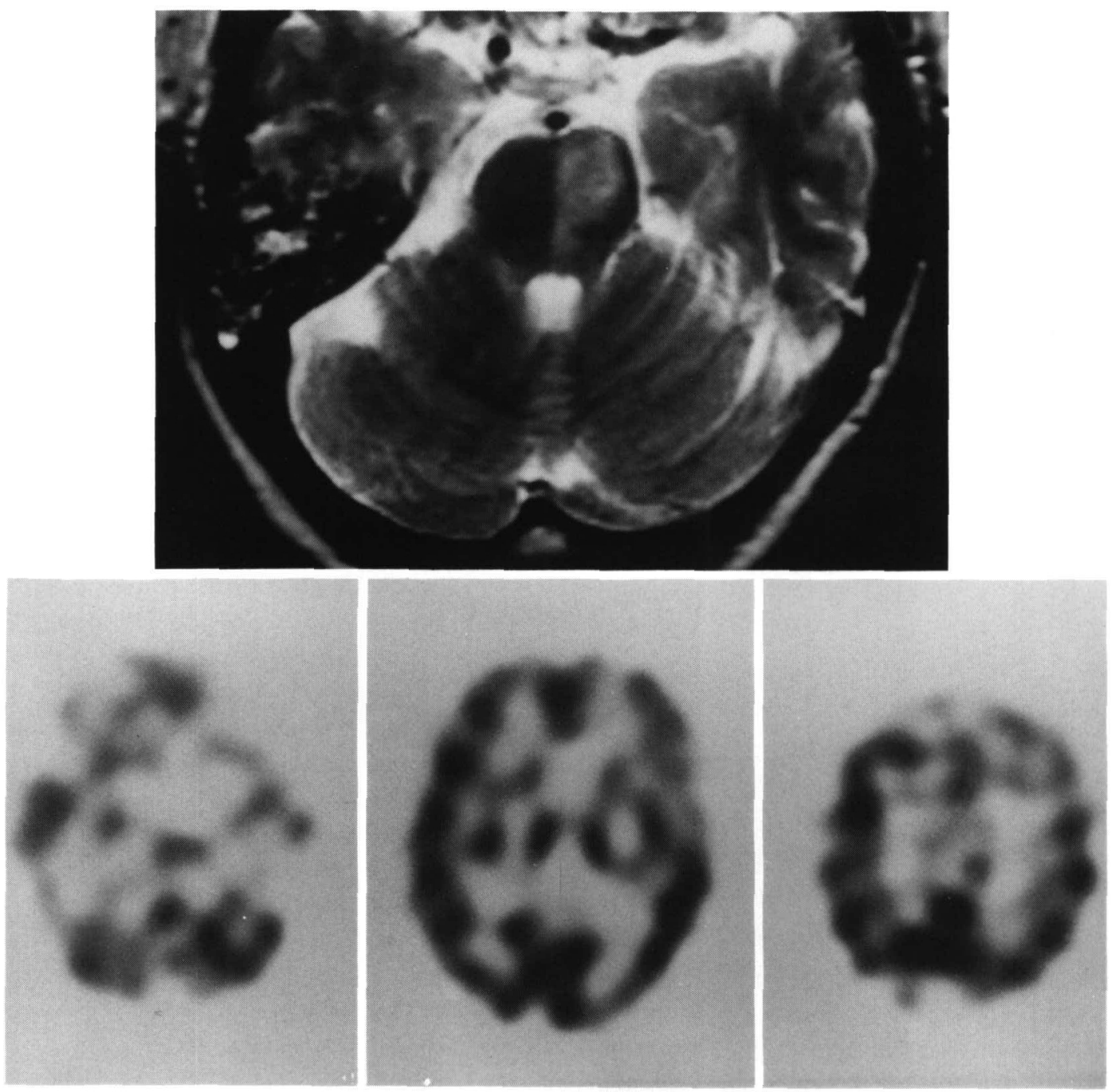

Fig. 1 MRI and SPECT images in case 3.

MRI (upper) reveals infarction of left upper pontine basis and tegmentum. Corresponding SPECT images (lower) show hypoperfusion of left frontal cortex (AI; +12.8\%) and right cerebellar hemisphere (AI; $-19.7 \%)$.

下部から同側被蓋を上行し，中脳・橋移行部で交叉後, 赤核を経て対側視床へ至り広範な大脳皮質領域へ投射 する. 一側小脳半球の血管障害で対側大脳半球の血流 低下が観察される場合があるが，この機序として小脳 視床皮質路を介した機能抑制が推測されているよう $に^{10) 11)}$, 脳幹病変の一部でも関与している可能性が高 い.ただし, SPECT 装置の解像力の限界から視床の血 流異常を正確に評価することは困難であった.しかし， 延髄に限局した病変ではこの神経路が障害されること はなく, 交叉前の橋上部病変で同側大脳半球に血流低
下が生じた機序の説明にも無理がある。ただし，MRI 軸位断層像からは上下方向の病巣範囲を正確に判定で きない場合もあり, 延䯣病変でも橋下部へ, また橋上 部病変でも中脳下部へ病変が伸展していた可能性は否 定できない。一方, 脳幹被蓋には広い範囲で網様体が 存在し,ここからの交叉性または非交叉性の投射線維 によって大脳皮質領域との機能的な連絡がある。これ らは意識や覚醒の保持に重要な役割を果たしている が, 特に中脳, 橋上部では大脳皮質に直接的な強い賦 活作用を与えているのに対し，橋下部，延髄では抑制 
的に作用しているとされる の交叉性また注非交叉性線維を介した，賦活的あるい は抑制的に作用する大脳半球の機能は, 脳幹背側病変 によって種々の影響を受けることは十分に予想され， 病巣部位に応じた複数の神経路を介して機能的影響が 生じるものと理解された。 また時には，両側性に大脳 半球の機能に影響を及济を場合も推定されるため，脳 血流量の左右差が明らかでない場合には判定が困難と なり，定量的な脳循環代謝測定法による評価も必要と なろう。

小脳半球の血流低下は，脳幹腹側（底部）病変で認 めやすく，橋中部から下部を境として上方病変で対側 にみられたことから，皮質橋小脳路を介した抑制効果 であることが推测された。これは, Sakai ら ${ }^{13)}$, Perani $ら^{14)}$, Fazekas ら"), Tsuda ら”の脳幹梗塞による症例 報告とも一致する。ただし，橋小脳路が両側に横走す る橋中部では，その病変によって両側小脳半球の機能 低下が生じる可能性もあり，病巣部位との対応につい てはさらに多数例での検討が必要と思われる，延䯣病 変では下小脳脚の障害によってオリーブ小脳路を介し た抑制機序が推測されたが，その頻度は 6 例中 1 例と 中脳，橋病変による場合と比較し少ない，これは，皮 質橋小脳路とオリーブ小脳路との解剖学的な入力線維 数の相違によるためと推測された。

また，大脳小脳問には交叉性の線維連絡を介した機 能的関連が, 種々の病的状態や健常者でも存在するこ とが知られている15).したがって,脳幹病変によって大 脳半球に生じた機能低下が二次的に対側小脳半球の機 能低下を引き起こしたり，あるいは反対に小脳半球の 機能低下が二次的に対側大脳半球の機能低下をもたら した可能性なども考慮する必要があるかもしれない。

可逆性の有無は diaschisisの定義とも関わる問題で あるが，発症後時間との関連では大脳半球の血流低下 は 1 2 2 力以内の比較的早期に認められた. 先に報 告した延髄外側梗塞の一部でも対側大脳半球の血流低

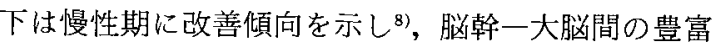
な線維連絡網から，一部に遮断が生じても他の線維連 絡を介した赋活作用などから機能的には徐々に回復し ていくものと推測された。しかし，小脳半球の血流低 下は急性期のみならず慢性期においても稀ならず観察 されたように, 病態的には diaschisis というよりも transneuronal degeneration との関連が窥われた。こ のことは crossed cerebellar diaschisisがしばしば長 期にわたり持続し16)17). 時には変性過程を経て肉眼的 萎縮（crossed cerebellar atrophy）へと発展する場合

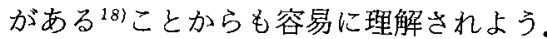

最後に, 遠隔部脳血流低下の臨床的意義については 不明確な点が多い. crossed cerebellar diaschisis の出 現と小脳症状との関連を認めたとする報告は一部でみ られるが19)，今回の成績のように一般的には関連を認 めないとするものが多い ${ }^{16) 17}$. diaschisis として観察 される血流低下の多くは軽度であり，直ちに症状が発 現するほどの低下ではないと推察される，臨床症状の 出現といった直接的な関連よりも，むしろその回復過 程や機能回復における代償機転などとの関連 ${ }^{20)}$ からも 検討を加えていく必要があると思われる.

謝辞：本研究に御協力をいただいた東京医科大学八王子 医療センター脳神経外科学・蓮江正道教授および原田病院 RI 室・下條 勝氏に媣謝いたします。また，ご校閲をいた だいた東京医科大学老年科・高崎 優教授に感謝申し上げ ます。

\section{文献}

1) Von Monakow C: Die Lokalization im Grosshirn und der Abbau der Funktion durch Kortikale Herde. Wiesbaden, JF Bergman, 1914, pp26 $-34$

2) Baron JC, Bousser MG, Comar D, et al: "Crossed cerebellar diaschisis" in human supratentorial brain infarction. Trans Am Neurol Assoc 105: 459-461, 1980

3) Feeney JC, Baron JC: Diaschisis. Stroke 17: 817-830, 1986

4）羽生春夫, 新井久之, 小林康孝ら：脳梗塞に打ける remote effects- ${ }^{123}$ I-IMP SPECT study-。核医 学 27:629-638, 1990

5) Fazekas F, Payer F, Valetitsch $\mathrm{H}$, et al : Brain stem infarction and diaschisis. A SPECT cerebral perfusion study. Stroke 24: 1162-1166, 1993

6) Rousseaux M, Steinling M, Mazingue A, et al : Cerebral blood flow in lateral medullary infarcts. Stroke 26 : 1404-1408, 1995

7) Tsuda $Y$, Ayada $Y$, Izumi $Y$, et al : Cerebellar diaschisis in pontine infarctions: A report of five cases. Eur J Nucl Med 22: 413-418, 1995

8）羽生春夫，嶺崎隆幸，大山 满ら：延髄外側梗塞 (Wallenberg症候群) 招ける大脳半球の血流低 下．神経内科 $48: 51-65,1998$

9) Fazekeas F, Chawluk JB, Alavi A, et al: MR 
signal abnormalities at $1.5 \mathrm{~T}$ in Alzheimer's dementia and normal aging. AJNR 149: 351356,1987

10) Sonmezoglu K, Sperling B, Henriksen $T$, et al : Reduced contralteral hemispheric flow measured by SPECT in cerebellar lesions: Crossed cerebral diaschisis. Acta Neurol Scand $87: 275$ $-280,1993$

11) Rousseaux $M$, Steinling $M$ : Crossed hemispheric diaschisis in unilateral cerebellar lesions. Stroke 23: $511-514,1992$

12) Carpenter MB: Core text of neuroanatomy. 2nd ed. Baltimore/London, Williams \& Wilkins, 1978, pp86-161

13) Sakai F, Aoki S, Kan S, et al: Ataxic hemiparesis with reductions of ipsilateral cerebellar blood flow. Stroke 17 : 1016-1018, 1987

14) Perani D, Lucignani G, Pantano $P$, et al: Cerebellar diaschisis in pontine ischemia. A case report with singlephoton emission computerized tomography. J Cereb Blood Flow
Metab 7: 127-131, 1987

15) Hanyu H, Arai H, Abe $S$, et al: Cerebrocerebellar relationships in normal subjects and patients with dementia of the Alzheimer type: a SPECT study. Ann Nucl Med 7 : 45-50, 1993

16) Pantano $P$, Baron JC, Samson $Y$, et al: Crossed cerebellar diaschisis. Further studies. Brain 109: 677-694, 1986

17）羽生春夫, 山口克彦, 岩本俊彦ら：Crossed cerebellar diaschisis $の$ 臨床的検討. 脳卒中 $11: 32$ $-39,1989$

18）羽生春夫, 山口克彦, 岩本俊彦ら：Crossed cerebellar diaschisis $と$ crossed cerebellar atrophy との関連について. CT 研究 11:155-160, 1989

19) Tanaka M, Kondo S, Hirai S, et al: Crossed cerebellar diaschisis accompanied by hemiataxia: A PET study. J Neurol Neurosurg Psychiatry $55: 121-125,1992$

20）羽生春夫，新井久之，小林康孝ら：Crossed cerebellar diaschisis の臨床的意義について. 神経内 科 $33: 392-394,1990$

\section{Abstract \\ Diaschisis in brain stem infarction \\ Haruo Hanyu, M.D. ${ }^{13)}$, Takayuki Minezaki, M.D. ${ }^{2)}$, Mitsuru Ohyama, M.D. ${ }^{2)}$, Takeshi Masui, M.D. ${ }^{2)}$ and Masayoshi Harada, M.D. ${ }^{2)}$ \\ ${ }^{1)}$ Department of Neurology, Harada Hospital \\ ${ }^{2)}$ Department of Neurosurgery, Harada Hospital \\ ${ }^{3)}$ Department of Geriatric Medicine, Tokyo Medical College}

We investigated 17 patients suffering from single unilateral brain stem infarction (in the midbrain in 2 patients, in the pons in 9, and in the medulla in 6) to elucidate their remote cerebral and cerebellar blood flow changes. Regional cerebral blood flow was evaluated semiquantitatively by SPEC $T$ and ${ }^{99 m}$ TcHMPAO, and the asymmetry index was calculated in certain regions of the cerebral cortex and cerebellum. A decreased cerebral blood flow was noted in 7 patients with infarction involving the dorsal brain stem, ipsilateral hypoperfusion occurred in patients with lesions situated rostrally to the upper pons, and contralateral hypoperfusion occurred in patients with lesions situated caudally to the upper pons, due probably to interruption of the cerebellothalamocortical pathways or damage to the fibers of the ascending reticular activating system. A decreased cerebellar blood flow was noted in 6 patients with infarction involving the ventral brain stem or cerebellar peduncle, contralateral hypoperfision occurred in patients with lesions situated rostrally to the middle or lower pontine basis, and ipsilaleral hypoperfusion occurred in patients with lesions in the meddula, suggesting damage to the corticoponetocerbellar or olivocerebellar pathways. Although cerebral hypoperfusion evident only within 1 or 2 months after stroke cerebellar hypoperfusion was commonly demonstrated at several months after stroke. Remote cerebral and cerebellar blood flow reductions are commonly observed in brain sterm infarction, probably associated with lesions of the projectional fiber tracts.

(Jpn J Stroke 20: 312-317, 1998) 